\title{
Singing Style of Jiangxi Folk Song
}

\author{
Xiaoying Guo \\ Department of music, Nanchang Normal University
}

Keywords: Style; Singing Skill; Motivation

\begin{abstract}
The singing style of Jiangxi folk song should be analyzed from two aspects. First,Researchers researchers should understand the motivation of the formation of its style, specifically analyze the folk song styles of different periods, regions, contents and genres, and give accurate positioning; second, Researchers researchers should master its certain singing skill, such as flat tune, glide, trill, etc., because certain style or characteristic is manifested by certain singing skill. Only by mastering accurate style and skilled technique and highly integrating with them can express the customs and lifestyles, and show the strong local characteristics of Jiangxi.
\end{abstract}

\section{Introduction}

The singing style of Jiangxi folk song should be analyzed from two aspects. First, researchers should understand the motivation of the formation of its style, specifically analyze folk song style of different periods, regions, contents and genres, and give accurate positioning; second, researchers should master its certain singing skill, such as flat tune, glide, trill, etc., because certain style or characteristic is manifested by certain singing skill. Only by mastering accurate style and skilled technique and highly integrating with them can express the customs and lifestyles, and show the strong local characteristics of Jiangxi.

On this piece of land rich in long history and culture, "Good products from the earth are nature's treasures, and the birth of heroes or great men brings glory to the place", in production and social practice from generation to generation, Jiangxi people created Jiangxi folk songs of which the content is rich, forms are diverse, lively and colorful, following the footsteps of history, Jiangxi folk song continuously develops, becoming a organic constitute part of our national cultural treasures rich ore.

As time passes, people's life is changing quickly, advanced science and technology make the world smaller and smaller, while people marvel at diverse and dazzling bright world music culture, talk and study symphony and "bel canto", reality also gives us a serious problem - in today of $21^{\text {st }}$ century, whether folk song, or Jiangxi folk song still develop ? How to develop?

Researchers believe that this comes down to dialectical relationship issue of "history" and "future". If there is no history, there is no present and future, if there is no past folk song, there is no Chinese music of the 21 st century. As an organic part of the Chinese national music culture, Jiangxi folk song made an indelible contribution for the long development of Chinese music, and this is the glorious past of Jiangxi folk song. In the future, Chinese music is required towards benign development, and similarly, the roots of Chinese music must be deep embedded in the folk music soil of Chinese earth, as what is called that of the nation of the world. Together with the rich and deep historical and cultural heritage in Jiangxi, Jiangxi folk song will become a necessary condition towards the development of Jiangxi music, so as to help Chinese music more national, more cosmopolitan with 
its own contribution.

Only by understanding Jiangxi folk song can one master Jiangxi folk song; only by mastering Jiangxi folk song can people develop Jiangxi folk song. Unfortunately, at present, study related to Jiangxi folk song just remains on the stage of excavation and preservation, in the aspects of how Jiangxi folk song follows the times, updates contents while on the basis of maintaining tradition and seeks new artistic life, there is little research, especially for the singing! (In fact, there are extensive types of Jiangxi folk song, and the singing is highly full of local color and lasting appeal, so the further exploration for its singing style will undoubtedly be an important part for promoting folk song singing career under the new era.

Researchers should understand the motivation of the formation of its style, specifically analyze folk song style of different periods, regions, contents and genres, and give accurate positioning; second, researchers should master its certain singing skill, such as flat tune, glide, trill, etc., because certain style or characteristic is manifested by certain singing skill. Only by mastering accurate style and skilled technique and highly integrating with them can express the customs and lifestyles, and show the strong local characteristics of Jiangxi.

\section{Title}

Jiangxi folk song has extensive types, and it can be divided into six categories by different singing environment, singing styles and singing functions, including work song, mountain song, minor, lantern song, custom song, children's song.

Work song. Work songs are divided into two major categories of water and land.

The rhyme of work song is generally short, vigorous and heavy, pause and transition of rhythm is remarkable, labor atmosphere is intense, artistic conception is full of strong driving sense, such as oil manufacturing work song, plate sawing work song, carrying work song, ramming work song and so on.

The work song is the rhyme song of water work, rhyme is long, it is of both singing and evocation, the tone is vigorous, free and easy, tunes are straight up and down, the penetration of work song is very strong, such as gang sawyer work song, boatman work song, boat towing work song, boat pushing work song and so on.

Mountain song. There are more, mostly are named after place names of various places, such as: Xingguo mountain song, Suichuan mountain song, Yongxin mountain song, etc. But there are also exception, for example, Duchang calls it "Guoshandiu", Ruichang calls it "Geshantuo", Longnan calls it "Guoshanliu" and so on.

According to music style and singing feature, mountain song can be divided into two kinds: high tune mountain song and flat tune mountain song.

As the name implies, the starting tune of mountain song is quite high, the song is mostly popular in huge mountain areas and old forest areas, and it is characterized by wide sentence, great undulating melodic line, free and varied meter, resounding and rough.

The tune of flat tune mountain song is smooth, prolongation of tune is quite short, emotion is fine and smooth, graceful and lyric. They are mostly popular in the plains and hilly areas.

What is worth mentioning in Jiangxi folk song is "Xingguo mountain song". This distinctive Hakkas mountain song is named after Xingguo County, and it get great reputation because of China Second Revolutionary Civil War. It uses the old singing method of forming the word with tune and impromptu use of the tunes, although the rhythm changes flexibly, there is still tune skeleton. The 
undulating of the whole mountain song is little, prolongation of tune is little, the tone composition of melody is heavy, and its representative "Aiyachao" is derived from exclamatory sentence in life, its tone changes with different emotions. The padding syllable before the finishing sentence "darling pattern" (or darling brother, darling sister, comrade pattern, etc.) is intended to increase intimacy and implies the coming of ending sentence. In addition to solo, Xingguo mo untain song takes antiphonal singing as the principal thing, the singers begin to have feeling as they see scene, completing a song extemporaneously, and they ask and answer each other to compete. The structure is generally made up of four lyrics (seven words per lyric).

Minor. Minor can probably be divided into two categories.

1. Xiangmai minor (some places call it playing tune). The tune is simple, local sense is strong, relatively colloquial, and among them, many minors are absorbed by local traditional opera music, such as Nanchang Banjiniang, Ruijin Niukudiao, and so on.

2. City minor

It gives priority to the form of sitting singing, often with accompaniment, the singing minor with more lyrics or multi-section body is mostly sung by artists with wide application.

Lantern song. Jiangxi lantern song is a kind of singing form taking colored-lantern marking as the main body and is of dance and song, and there are festival dancing songs and songs sung in some folk-custom activities. The centralized reflection of traditional national custom is the so-called "festive lantern festival", which is very popular all over Jiangxi. Every New Year, different patterns of colored-lantern marking, singing and dancing performances of singing lantern, jumping lantern, dancing lantern, playing lantern decorate the festival joyously.

There are many varieties of colored-lantern marking, among which, the tea blue lantern is more famous and popular.

The music of lantern song mostly developed and changed from minor. Lining tunes alternate them (the use of padding syllable is generally identical with song content), the accompaniment mostly uses instruments like gongs and drums, blowing and beating instrument, lively and cheerful, mood is witty and lively.

Custom song. Jiangxi custom song refers to the song sung in folk custom activities like wedding-funeral, healing, worship and festivals. The music features are mostly displayed in songs of ceremony like marriage celebration are with speaking and singing, sincere and joyous; crying marrying, crying for the dead are as if weeping and complaining, in a tearful voice, with strong life flavor and local color. Melody is much narrative and colloquial. There is also life tones like "Selling tea egg", "Selling spiced broad beans", they are with strong life flavor.

Children's song. Jiangxi children's song is divided into children's song and cradle song.

Children's song is the song sung by children when they pasture cattle and raise cattle. The music features are quite colloquial melody, concise words, and lucid and lively rhythm with naive and lively children's fun.

Cradle song is the song sung by the mother when she coaxes the baby to sleep. The tone is sincere and euphemistic, reflecting the deep mother's love.

Folk songs with different types have different singing styles. In order to accurately grasp the singing style of Jiangxi folk song, people must also study the motivation of formation of their style.

In some sense, the folk song reflects arepublic mind, popular sentiment and folk custom under certain historical environment. Long historical culture and the rich and colorful life bring diversity to subject matter and content of Jiangxi folk song. 
Su region folk song directly serves for revolutionary struggle, different contents are sung in different occasions, and its theme thought is distinct. For example, riot teams had "Riot song", Red Guards had "Red guard song", children teams had "Standing sentry song": in Red Army, there were pre-war mobilization, celebration for the victory after the war, battlefield propaganda, assault and kill the enemy, all of which were all accompanied by their corresponding newly filled folk song to strengthen military might.

Of course, traditional folk song (including historical revolutionary folk song) and new folk song are different in the style of the times. The new folk song is more cheerful in qualities, more lively in style and more stretching in emotion.

The type of Jiangxi folk song can be divided into six categories, including work song, mountain song, minor, lantern song, custom song and children's song. The type itself and its style performance, in a sense, is the concentrated reflection of geographical environment in Jiangxi folk song. Now from the reflection of geographical environment of five regions of middle Jiangxi, northeast Jiangxi, northwest Jiangxi, west Jiangxi and south Jiangxi on types and style performance of folk song are described as follows:

Middle Jiangxi is located in the southeast coast of Xieyang Lake. In the whole region, water and land transportation are relatively developed, the land is fertile, rivers and ports are in length and breadth stretching to the horizon, and it is an abundant place in Jiangxi, a natural granary. People of middle Jiangxi live in this fields and gardens and water village of beautiful scene, the overall style of various types of folk songs are known for their stretching and openness, graceful and melodious, they are of countryside prospect of plain area.

Northeast Jiangxi is located in east Ganfu plain. Duhu plain is in the west part, hills are in the central part, mountains are in east, south and north part. Since it is on the border of western Zhejiang, the style of folk song is with both the beauty and euphemism of Yangtze River south folk song and simpleness and honesty of Jiangxi folk song.

Northwest Jiangxi is located in the south coast of middle and lower Yangtze River, close to Duyang Lake. It adjoins three provinces of Hunan, Hubei and Anhui in its northwest part, it is adjacent to the Yangtze River in the north, Duyang Lake is in its southeastern part, hills and mountain areas are in its northwest part, it is a comprehensive area of lakes, rivers and plains.

West Jiangxi is in junction with eastem Hunan, and the famous Jinggangshan is in its western part. West Jiangxi folk songs are especially highlighted by mountain song and minor. Taking mountain song as an example, the high tune mountain songs in mountain song category are mostly popular in the western high mountain areas, the tone is resounding and rough, melodic line is undulating, meter is free and varied, shuai tune mostly use "hey Lonrho". Most of flat tune mountain songs are popular in plain and hilly areas, the tune is smooth and melodious, and sentence of prolongation of tune is short.

In southern Jiangxi areas, except the southern Jiangxi basin in central and northern part, in most areas, mountains are ups and downs, and forests are flourishing. Big or small rivers basin valley and hills inlay in between.

Because southern Jiangxi is rich in forests production, therefore there is complete set of lumbering work song and gang sawyer work song. The mountain song is energetic and simple, resounding and bold and unconstrained, and especially the "Guoshanliu" of Longnan County, its singing is with loud voice, penetrating, quite imposing. The mountain areas are rich in tea, each year at the time of "open tea mountain"(pick tea) and "open tea market"(selling tea), tea farmers will celebrate greatly, so a lot 
of good month songs and minor emerge. The melody of lantern song which is singing and dancing joyously with colored-lantern marking as its main body is lively, its rhythm is strong. Minor is strong in melody, tactful and smooth.

When analyzing the musical scale mode of Jiangxi folk song, researchers find that in Jiangxi folk song, there is a few musical scale mode composed with two-tune and three-tune. Such as the "62626" feature tone composed of "62" two tunes is the melody made up of varied and repeated single sentence, each phrase mostly falls on feather tune, melody has repeated multi unison and pure four degrees jumped, tune starts high and falls low, forming a oblique curve proceeding detouring, to the end of the song, feather tune appears, falling on the "feather tone" in the end.

"The pattern of music is in the song, and color is in the singing". In a sense, the proper use of singing skills is the expression of a style - certain style characteristics must be expressed by certain singing skills, otherwise even people know the style features, they still can not manifest. Obviously, if a singer is not able to well grasp the characteristics of folk song singing method of a particular region, it also weakened the color of the folk song, and it has no difference with singing ordinary songs.

Now the main singing skills of Jiangxi folk songs are described as follows:

"Flat tune" refers to singing with real voice, or singing by combination of real and false voice with real voice-based, it applies to some smooth tunes, being featured by limited range and exquisite emotion. The singing of Jiangxi folk songs is mostly "flat tune singing".

Thin tune is mostly a singing method by women who sing alone. Tune is small, and tones are quiet and delicate, pleasant.

In Jiangxi folk song singing skills, the ornament tone is a very important part, it is widely used in folk song singing. Often for a folk song with simple tune, based on the content, feeling, dialect and tone, after the singer adds various decorative tone, the melody is greatly enriched, and the singing effect is enhanced.

The use of glide skills in folk song singing process not only makes the melody more graceful and euphemistic, but also increases the sense of movement to melody. Because of this, glide singing skills became one of the most important and the most unique expression in Jiangxi folk song singing, singing with glide can be heard in mountain song, minor or lantern song, for example, in "Xingguo mountain song", the second bar close to the song head "ai ya chao" - a high pitch prolongation of tune after the highest pitch of the song, mostly using glide singing.

Glide is divided into great glide, small glide, and the use of lower glide is most common. When singing, vocal cords first tension, then relax to sing, to sing smooth and natural is better.

Even and tremble voice is a symbol of man's excitement. This singing skill has also appeared more frequently in folk song singing. There is a saying in "Guwulu": "Shake in the song is most likely to please. It should start powerful, go peaceful, end elegant, natural for listening. It should not be off-size and ambiguous. It seems like yes but in fact no, it is beyond dispute. Those who is good at using shake can not be too many, more are lack of freshness." Here the word "shake" sound is the "trill". These sentences not only describe the singing method of shake but also point out the mistake that easy to make. Using should not be much, it should be used in position, sing just right.

The nine kinds of singing skills such as the above said high tune, flat tune, portamento, and vibrato are the main singing skills of Jiangxi folk song. It should be noted that skill is for showing style. Only by mastering certain skills one can perform the style better. However, skill is not single, singing a Jiangxi folk song well does not depend on mastering one or two singing skills, but instead, one 
should accumulate little by little in learning and singing practice, and ultimately incorporate a variety of skills in the song, in order to achieve the combination of skills and style. Skills with no style do not exist, and skill is manifested through style. However, times are changing, and people's life interest and aesthetic concepts are also changing, so the singing style of Jiangxi folk song will also change accordingly, in order to reflect emotion of the people of the new historical period. It is an important part of the singing style, so the singing skills should begin to react first.

In Jiangxi, regardless of rivers and lakes, hills and plains, large mountains and forests area, there are mountain songs representing local language style and aroma, they make singer feel when he see the scene, sing while completing the song, they express what they see and what they think, what they want to say with rhythmic and tune trope living language.

In history, Jiangxi is in the heart of Wu Culture and Chu Culture, and it is in the junction of several provinces geographically, which makes part of folk songs inevitably left with the mark of edge transitional style. For example, the folk song style of northeast Jiangxi is of both the generality of Yangtze River south folk song and colorful Gan Wu edge transitional characteristics.

To a large extent, folk song is divided by the singing functions. For example, work songs include lumbering work song, oil production work song, spring rice work song, boat towing work song, rafting work song and so on. Moreover, different labors have different rhythm, which is related with intensity of labor and the speed of actions. The aim is to unify rhythm and improve labor efficiency.

In the folk song singing, functionality of folk songs should be highlighted - cradle song must be sung in a serene, gentle and smooth manner, because it aims to make children fall asleep; Yue song must be sung happily and smoothly, because it aims to celebrate bamboo; Gaosheng mountain songs must be sung in a resounding, loud and straight way, because Gaosheng mountain songs are related with mountainous and forests areas, as it is said, "just hear songs but see no one"........

\section{Conclusions}

After inheriting Gan Yue culture and Yang Yue culture, Jiangxi folk song has experienced thousands of years of historical development and changes. Although it was in between the two center areas of $\mathrm{Wu} \mathrm{Culture}$ and $\mathrm{Chu}$ Culture, it can also be outstanding and gain much recognition. In general, she was full of primitive simplicity of grand of Chu culture and graceful beauty of $\mathrm{Wu}$ culture. In mountainous areas, folk songs are bold, free, firm and optimistic, mostly pliable, mild, bright and beautiful, and many beautiful folk songs win universal praise with long-lasting life. Research on its singing style has reflected high demand of new era on folk songs. However, the singing skill or singing style cannot be the same all the time. Researchers have a long way to go for understanding of Jiangxi folk song, mastering Jiangxi folk songs, developing Jiangxi folk song, and enriching its singing style.

\section{References}

[1] Judd E R. Revolutionary drama and song in the Jiangxi Soviet[J]. Modern China, 1983: 127-160.

[2] $\mathrm{Mu}$ Y. Academic ignorance or political taboo? some issues in China's study of its folk song culture[J]. Ethnomusicology, 1994: 303-320.

[3] Jones S. Reading between the Lines: Reflections on the Massive" Anthology of Folk Music of the Chinese Peoples"[J]. Ethnomusicology, 2003: 287-337. 
[4] Kuo-Huang H. Folk Songs of the Han Chinese: Characteristics and Classifications[J]. Asian music, 1989: 107-128.

[5] Xin W. Reflections on the Singing Style of Chinese Folk Songs [J][J]. Journal of Jiangxi Science \& Technology Normal University, 2009, 6: 028.

[6] Mittler B. "Eight Stage Works for 800 Million People"*: The Great Proletarian Cultural Revolution in Music-A View from Revolutionary Opera[J]. The opera quarterly, 2010, 26(2-3): 377-401.

[7] Ting Y. New Folk Music_— the Modern Expression of Chinese Traditional Music Culture [J][J]. Journal of Jiangxi Science \& Technology Teahers' College, 2005, 3: 025.

[8] Fei W. The operating skill of the Chinese tradition drama to sing in the use of thenational operating vocal music [J][J]. Journal of Hubei Radio \& Television University, 2008, 8: 044.

[9] Xu-hua L. A Comparative Study on Hakka Folk Songs in West Fujian and in South Jiangxi[J]. Journal of Longyan University, 2010, 4: 033.

[10] Zhong Q J. Han Folk Song in China[J]. Tradition \& Change Performance, 2013: 35. 